\title{
Análise de casos de AIDS em Santa Cruz do Sul
}

\author{
Letícia Trivilin ${ }^{1}$; Gabson Araújo Aragonez² Monique Emanuelli ${ }^{3}$ \\ Daniela Teixeira Borges ${ }^{4}$ Alexandre Rieger ${ }^{5}$
}

\section{Resumo}

Foi realizado um estudo bibliográfico-documental por meio de análise quali-quantitativa de informações resgatadas das bases de dados nacionais como o DataSUS e Departamento de DST, AIDS e Hepatites Virais da Vigilância em Saúde com foco na Síndrome da Imunodeficiência Adquirida (AIDS) na população de Santa Cruz do Sul (SCS). O objetivo foi realizar uma comparação dos dados do município de SCS com os dados estaduais e nacionais de modo a compreender se as políticas públicas de saúde têm sido eficazes quanto a prevenção, especialmente no âmbito da população mais jovem. A análise dos dados sugere que no município de Santa Cruz do Sul havia uma queda na razão de sexo (masculino/feminino) nos anos de 2011 e 2012 para um valor próximo de 1,0, porém voltou a subir para uma razão de 2 homens para 1 mulher nos anos de 2013 e 2014, sendo que o mesmo foi observado em nível nacional. Entretanto, o fator preocupante é o aumento na taxa de detecção de casos por 100.000 habitantes em SCS nos anos de 2013 e 2014, principalmente na população jovem entre 15 a 24 anos. Enquanto esta taxa estava próxima de 10 casos por 100.000 habitantes entre 2005 a 2012, observou-se que dobrou em

\footnotetext{
1 Acadêmica do curso de medicina da Universidade de Santa Cruz do Sul. E-mail: leti_tt@hotmail.com

${ }^{2}$ Acadêmico do curso de medicina da Universidade de Santa Cruz do Sul.

${ }^{3}$ Acadêmica do curso de medicina da Universidade de Santa Cruz do Sul.

${ }^{4}$ Médica de família e comunidade e professora do curso de medicina da Universidade de Santa Cruz do Sul.

${ }^{5}$ Professor do Departamento de Biologia e Farmácia da Universidade de Santa Cruz do Sul.
} 
2013 e em 2014 aumento quase 5 vezes atingindo 51,9 casos. Estes resultados sugerem que o trabalho de prevenção e esclarecimento das populações alvo provavelmente não está gerando os resultados desejados. Somando-se ao fato de o Rio Grande do Sul ser o segundo estado com maior número de casos absolutos HIV/AIDS positivos há a relação com o subtipo viral prevalentemente infectante do estado que é o subtipo $\mathrm{C}$ do vírus HIV-1, o qual é tido como sendo menos virulendo, permanecendo mais tempo assintomático, aumentando assim o período onde a pessoa infectada pode estar transmitindo a doença sem seu conhecimento. Com o intuito de diminuir os casos de HIV/AIDS na cidade, busca-se a prevenção por exemplo, com a utilização de preservativos, masculino e feminino, sendo essa a forma mais eficiente de evitar a contaminação por contato sexual. Além disso, é de suma importância investimentos para a conscientização, palestras, panfletagem e demais meios de comunicação para a educação da população sobre a forma de transmissão, controle e manejo da doença.

Palavras-chave: Santa Cruz do Sul. HIV-AIDS. Relação masculino-feminino. 